\title{
What does it take to improve nationwide healthcare quality in China?
}

\author{
Xi Li, ${ }^{1}$ Harlan M Krumholz (D) ${ }^{2}$
}

- Additional material is published online only. To view please visit the journal online (http://dx.doi.org/10.1136/ bmjas-2019-009839)

${ }^{1}$ National Clinical Research Center of Cardiovascular Diseases, Fuwai Hospital, Chinese Academy of Medical Sciences and Peking Union Medical College, Beijing, China ${ }^{2}$ Center for Outcomes Research and Evaluation (CORE), Yale New Haven Hospital, New Haven, Connecticut, USA

\section{Correspondence to}

Dr Harlan M Krumholz, Center for Outcomes Research and Evaluation (CORE), Yale New Haven Hospital, New Haven, CT 06510, USA

harlan.krumholz@yale.edu and Dr Xi Li, National

ClinicalResearch Center of Cardiovascular Diseases, Fuwai Hospital, Chinese Academy ofMedical Sciences and Peking Union Medical College, Beijing, China; xil.i@fwoxford.org

Accepted 12 July 2019 Published Online First 31 July 2019

\section{Linked}

- http://dx.doi.org/10.1136/ bmjqs-2018-008938

\section{Check for updates}

(C) Author(s) (or their employer(s)) 2019. No commercial re-use. See rights and permissions. Published by BMJ.

To cite: Li X, Krumholz HM. BMJ Qual Saf

2019;28:955-958.
Despite the great strides that have been made during China's recent healthcare reform to improve access to healthcare, ${ }^{1}$ substantial gaps in quality persist. ${ }^{2}$ In a study of 33 tertiary hospitals in China, Jian and colleagues reported no improvement in most process indicators on healthcare quality for acute myocardial infarction, cerebral ischaemic stroke, chronic obstructive pulmonary disease and bacterial pneumonia, from 2013 to $2018 .^{3}$ This study provides the most contemporary evidence of quality trends during a 5 -year period after the launch of China's healthcare reform. More importantly, it covers a broad set of treatments for four common clinical conditions that are commonly used for assessing healthcare quality. ${ }^{4-9}$

The poor performance and lack of improvement in Chinese hospitals revealed in this study aligns with prior findings. In a nationally representative study on ST-segment elevation myocardial infarction (STEMI) from 2001 to 2011, no improvement was found in in-hospital mortality outcomes, which may be a result of the continued underuse of reperfusion therapy and other recommended treatments. ${ }^{10}$ Through comparisons between urban and rural hospitals, the same study also found that despite differences in treatment and the availability of advanced facilities, outcomes for patients admitted to rural hospitals were similar to those of patients who were admitted to urban hospitals, indicating that the additional resources available at urban hospitals did not result in greater benefits to patients. ${ }^{11}$ Given the tremendous political commitment and financial investment in China's healthcare reform during the past decade, it is critical to understand how to improve nationwide healthcare quality.
An important step toward improvement is to understand the reasons underlying the current quality of care in China. Overall, performance measurements are inadequate. ${ }^{2}$ The government established a nationwide claims data system-the Hospital Quality Monitoring System (HQMS) - to collect a common dataset of information from all inpatient medical records in tertiary hospitals. However, except for reporting crude in-hospital mortality rate and length of stay, the measurements have rarely been used to identify quality gaps or to develop improvement strategies. In addition, there are few incentive mechanisms to link performance with the interests of care providers. ${ }^{2}$ Payments to healthcare providers in China are mainly under the fee-for-service model, which is based on the amount of services provided rather than the appropriateness of the processes or the success of the outcomes. ${ }^{12}$

Improvements in quality of care are not easy to achieve. Through a comprehensive literature search, we identified several trials designed to develop and evaluate hospital-level quality improvement strategies for cardiovascular disease care (online supplementary table), ${ }^{13-25}$ but gaps in knowledge remain. First, the findings on effectiveness in these studies were mixed, with about half showing no difference even though most used targeted performance feedback as one of the main strategies. Second, most of the studies focused on process indicators related to individual behaviours that are easy to change, such as medications in the hospital and at discharge, rather than more difficult ones that require multidisciplinary collaboration, such as the use or timeliness of reperfusion therapies. Third, the changes in process indicators 
achieved in these studies did not always improve patients' outcomes; for example, a stepped-wedge trial on care for acute coronary syndromes found no significant effect on in-hospital outcomes, despite showing improvement in early antiplatelet treatment and other care process indicators. ${ }^{25}$

Nevertheless, there are notable successes such as the nationwide door-to-balloon (D2B) Alliance in the USA. The D2B Alliance, initiated by the American College of Cardiology and comprising a group of more than 1000 hospitals, was developed to improve D2B times for patients with STEMI who undergo primary percutaneous coronary intervention. Based on the six key strategies for hospitals to reduce D2B times developed via nationwide qualitative and quantitative studies, educational sessions that disseminated information about innovative approaches and provided information about experiences at various sites were conducted. ${ }^{26}$ From July to September 2006, 54\% of patients received primary percutaneous coronary intervention within $90 \mathrm{~min}$. This number increased significantly during the study period, to $75 \%$ from January to March $2008 .{ }^{27}$ Moreover, the shorter D2B times were consistently associated with lower mortality over time. ${ }^{28}$

Another example is the Chinese Cardiac Surgery Registry (CCSR), which consists of 102 urban tertiary hospitals in China. In the CCSR, comprehensive performance feedback and targeted technical support has been provided by the China National Center for Cardiovascular Diseases (NCCD) since 2004. In addition to the site-specific performance feedback report with analysis regarding patient characteristics, surgical processes and in-hospital outcomes in unadjusted and risk-adjusted formats, the NCCD provides participating hospitals an array of technical support such as seminars, on-site assistance and training programme. Cardiac surgical teams at NCCD visited 20-30 participating hospitals annually to provide on-site guidance and share practical experiences with local teams. In the past 3 years, 696 trainees, including cardiac surgeons, anaesthetists and cardiopulmonary bypass doctors, attended NCCD's training programmes for 5 months on average. Two recent studies found improvements in isolated coronary artery bypass graft-related in-hospital mortality, major complication rates and length of stay from 2004 to $2013 .{ }^{29}$ In elderly patients, in-hospital mortality after coronary artery bypass graft surgery has been gradually approaching the level observed in hospitals in the USA. ${ }^{30}$

Compared with the well-conducted trials in the online supplementary table, the D2B Alliance and CCSR had a successful two-pronged approach: ongoing efforts spanning many years to change care provider behaviours and consequently patient outcomes, and targeted technical support that demonstrated how to improve in conjunction with performance feedback that specified what to improve.
Thus, several combined efforts are needed to improve healthcare quality. To establish sustainable mechanisms for quality assessment and improvement, national information platforms in China-such as the HQMS and social medical insurance-need to be configured to capture and integrate data from everyday practice nationwide. Also, the government could increase performance accountability through payment policies such as those that were recently issued on diagnosis-related groups to reward high-quality and high-value care. In addition, to provide targeted technical support in specific clinical fields, leading hospitals could collaborate by taking responsibility for disseminating their knowledge and experiences to local, poorer performing hospitals. The national medical science centres and regional medical care centres, ${ }^{31}$ in the planning stage by the government, could play key roles in this effort, particularly through the healthcare alliance with collaborations between hospitals of varied levels.

We agree with Jian and colleagues that during this new era of healthcare reform, with its strong focus on quality and efficiency, the Chinese government should invest increased effort in promoting a quality agenda. ${ }^{32}$ An overarching strategy for nationwide quality improvement is to build a learning health system $^{2}$ in which the data generated in the ongoing delivery of care should be leveraged to produce insights and discoveries that are made available to providers to improve care and performance. Outcomes and implementation research surrounding monitoring the performance of providers and comparative effectiveness of strategies could act as engines to generate and evaluate new knowledge in a rapid cycle of identifying targets, intervening to improve and assessing the effects. It is not only about what strategies work in which populations-it is also about how best to ensure that care is optimally delivered. Such a learning health system will be able to ensure appropriate treatments and optimised outcomes in China, and provide lessons for other countries facing similar challenges.

Funding This research was partly supported by the National Key Research and Development Program (2017YFC1310803) from the Ministry of Science and Technology of China

Competing interests HMK was a recipient of a research grant, through Yale, from Medtronic and the US Food and Drug Administration to develop methods for postmarket surveillance of medical devices; was a recipient of a research grant with Medtronic and Johnson \& Johnson, through Yale, to develop methods of clinical trial data sharing; was a recipient of a research agreement, through Yale, from the Shenzhen Center for Health Information for work to advance intelligent disease prevention and health promotion; collaborates with the National Center for Cardiovascular Diseases in Beijing; received payment from the Arnold \& Porter Law Firm for work related to the Sanofi clopidogrel litigation and from the Ben C. Martin Law Firm for work related to the Cook IVC filter litigation; chairs a Cardiac Scientific Advisory Board for United Health; is a participant/participant representative of the IBM Watson Health Life Sciences Board; is a member of the Advisory Board for Element Science, the Advisory Board for 
Facebook and the Physician Advisory Board for Aetna; and is the founder of Hugo, a personal health information platform. $\mathrm{Xi}$ Li has no potential conflicts to report.

Patient consent for publication Not required.

Provenance and peer review Commissioned; internally peer reviewed.

\section{ORCID iD}

Harlan M Krumholz http://orcid.org/0000-0003-2046-127X

\section{REFERENCES}

1 Meng Q, Xu L, Zhang Y, et al. Trends in access to health services and financial protection in China between 2003 and 2011: a cross-sectional study. The Lancet 2012;379:805-14.10.1016/S0140-6736(12)60278-5

2 Jiang L, Krumholz HM, Li X, et al. Achieving best outcomes for patients with cardiovascular disease in China by enhancing the quality of medical care and establishing a learning healthcare system. The Lancet 2015;386:1493-505.10.1016/S01406736(15)00343-8

3 Jian W, Figueroa J, Woskie L, et al. Quality of care in large Chinese hospitals: an observational study. BMJ Qual Saf 2019;28:963-70.

4 Wang Y, Liao X, Zhao X, et al. Using recombinant tissue plasminogen activator to treat acute ischemic stroke in China: analysis of the results from the Chinese national stroke registry (CNSR). Stroke 2011;42:1658-64.

5 Cho KH, Nam CM, Lee SG, et al. Measuring of quality of care in patients with stroke and acute myocardial infarction: an application of algebra effectiveness model. Medicine 2019;98:e15353.

6 Ellerbeck EF, Jencks SF, Radford MJ, et al. Quality of care for Medicare patients with acute myocardial infarction. A fourstate pilot study from the cooperative cardiovascular project. JAMA 1995;273:1509-14.

7 Jørgensen M, Mainz J, Lange P, et al. Quality of care and clinical outcomes of chronic obstructive pulmonary disease in patients with schizophrenia. A Danish nationwide study. Int J Qual Health Care 2018;30:351-7.

8 Meehan TP, Fine MJ, Krumholz HM, et al. Quality of care, process, and outcomes in elderly patients with pneumonia. JAMA 1997;278:2080-4.

9 Mularski RA, Asch SM, Shrank WH, et al. The quality of obstructive lung disease care for adults in the United States as measured by adherence to recommended processes. Chest 2006;130:1844-50.

10 Li J, Li X, Wang Q, et al. ST-segment elevation myocardial infarction in China from 2001 to 2011 (the China PEACE-Retrospective acute myocardial infarction study): a retrospective analysis of hospital data. The Lancet 2015;385:441-51.10.1016/S0140-6736(14)60921-1

11 Li X, Murugiah K, Li J, et al. Urban-Rural comparisons in hospital admission, treatments, and outcomes for ST-segmentelevation myocardial infarction in China from 2001 to 2011. Circulation 2017;10.

12 Yip W, Hsiao W. Harnessing the privatisation of China's fragmented health-care delivery. The Lancet 2014;384:805-18.10.1016/S0140-6736(14)61120-X

13 Carlhed R, Bojestig M, Wallentin L, et al. Improved adherence to Swedish national guidelines for acute myocardial infarction: the quality improvement in coronary care (QUICC) study. Am Heart J 2006;152:1175-81.10.1016/j.ahj.2006.07.028
14 Brush JE, Rensing E, Song F, et al. A statewide collaborative initiative to improve the quality of care for patients with acute myocardial infarction and heart failure. Circulation 2009;119:1609-15.

15 Du X, Gao R, Turnbull F, et al. Hospital quality improvement initiative for patients with acute coronary syndromes in China: a cluster randomized, controlled trial. Circ Cardiovasc Qual Outcomes 2014;7:217-26.

16 Flather MD, Booth J, Babalis D, et al. Improving the management of non-ST elevation acute coronary syndromes: systematic evaluation of a quality improvement programme European quality improvement programme for acute coronary syndrome: the EQUIP-ACS project protocol and design. Trials 2010;11:5.

17 Flather MD, Babalis D, Booth J, et al. Cluster-Randomized trial to evaluate the effects of a quality improvement program on management of non-ST-elevation acute coronary syndromes: the European quality improvement programme for acute coronary syndromes (EQUIP-ACS). Am Heart J 2011;162:700-7.

18 Lewis WR, Peterson ED, Cannon CP, et al. An organized approach to improvement in guideline adherence for acute myocardial infarction: results with the get with the guidelines quality improvement program. Arch Intern Med 2008;168:1813-9.

19 Soumerai SB, McLaughlin TJ, Gurwitz JH, et al. Effect of local medical opinion leaders on quality of care for acute myocardial infarction: a randomized controlled trial. JAMA 1998;279:1358-63.

20 Alexander KP, Wang TY, Li S, et al. Randomized trial of targeted performance feedback to facilitate quality improvement in acute myocardial infarction care. Circ Cardiovasc Qual Outcomes 2011;4:129-35.

21 Sauaia A, Ralston D, Schluter WW, et al. Influencing care in acute myocardial infarction: a randomized trial comparing 2 types of intervention. Am J Med Qual 2000;15:197-206.

22 Beck CA, Richard H, Tu JV, et al. Administrative data feedback for effective cardiac treatment: affect, a cluster randomized trial. JAMA 2005;294:309-17.

23 Berwanger O, Guimarães HP, Laranjeira LN, et al. Effect of a multifaceted intervention on use of evidence-based therapies in patients with acute coronary syndromes in Brazil. JAMA 2012;307:2041-9.10.1001/jama.2012.413

24 Berwanger O, Guimarães HP, Laranjeira LN, et al. A multifaceted intervention to narrow the evidence-based gap in the treatment of acute coronary syndromes: rationale and design of the Brazilian intervention to increase evidence usage in acute coronary syndromes (BRIDGE-ACS) clusterrandomized trial. Am Heart J 2012;163:e1:323-9. 29.

25 Wu Y, Li S, Patel A, et al. Effect of a quality of care improvement initiative in patients with acute coronary syndrome in resource-constrained hospitals in China. JAMA Cardiol 2019;4:418-27.10.1001/jamacardio.2019.0897

26 Krumholz HM, Bradley EH, Nallamothu BK, et al. A campaign to improve the timeliness of primary percutaneous coronary intervention: door-to-balloon: an alliance for quality. JACC Cardiovasc Interv 2008;1:97-104.

27 Nallamothu BK, Krumholz HM, Peterson ED, et al. Door-ToBalloon times in hospitals within the get-with-the-guidelines registry after initiation of the door-to-balloon (D2B) alliance. Am J Cardiol 2009;103:1051-5.

28 Nallamothu BK, Normand S-LT, Wang Y, et al. Relation between door-to-balloon times and mortality after primary 


\section{Editorial}

percutaneous coronary intervention over time: a retrospective study. The Lancet 2015;385:1114-22.10.1016/S01406736(14)61932-2

29 Yuan X, Zhang H, Zheng Z, et al. Trends in mortality and major complications for patients undergoing coronary artery bypass grafting among urban teaching hospitals in China: 2004 to 2013. Eur Heart J Qual Care Clin Outcomes 2017;3:312-8.

30 Zheng Z, Zhang H, Yuan X, et al. Comparing outcomes of coronary artery bypass grafting among large teaching and urban hospitals in China and the United States. Circulation 2017;10.

31 Central Committee CPC,State Council. The Plan for "Health China 2030", 2016. Available: http://www.gov.cn/xinwen/ 2016-10/25/content_5124174.htm [Accessed June 28, 2019].

32 Xinhua News Agency. Interpretation on "the guiding opinions on the establishment of modern hospital management system" by the head of the Medical Reform Office of the State Council, 2017. Available: http://www.gov.cn/xinwen/2017-07/26/ content_5213541.htm [Accessed 28 Jun 2019]. 